\title{
PReS-FINAL-2226: Assessment of autonomic functions in children with Familial Mediterranean Fever by using heart rate variability measurements
}

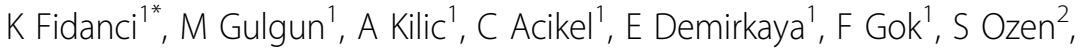 \\ FMF Arthritis Vasculitis and Orphan disease Research in Paediatric Rheumatology (FAVOR) \\ From 20th Pediatric Rheumatology European Society (PReS) Congress \\ Ljubljana, Slovenia. 25-29 September 2013
}

\section{Introduction}

Familial Mediterranean Fever (FMF) is an autoinflammatory disorder characterized by recurrent fever associated with inflammation of serous membranes. There is no study reporting the assessment of autonomic functions by using heart rate variability (HRV) in children with FMF. HRV is a practical and reliable method for evaluation of autonomic functions. HRV studies have pointed to the presence of autonomic dysfunctions in many autoinflammatory disorders, possible contributing factors to ventricular tachyarrhythmias and sudden cardiac death in these patients.

\section{Objectives}

In this study, we investigated possible alterations in cardiac autonomic functions and other probable cardiac effects in children with FMF by HRV analyses and conventional echocardiography.

\section{Methods}

The study population included 70 consecutive patients with FMF who were examined at our Cardiology and Rheumatology Departments (27 female; mean age 11.14 \pm 3.536 years) and 50 healthy control subjects $(20$ female; mean age $10.68 \pm 3.107$ years). All FMF patients enrolled in our study fulfilled the clinical criteria for FMF. The control group was consisted of fifty healthy volunteers matched for age and gender without history of any cardiac or systemic inflammatory disease. All patients were using regular colchicine therapy, clinical and laboratory assessment of FMF patients were performed during an attack-free period.

In each patient, it was performed twelve lead electrocardiography (ECG) at $25 \mathrm{~mm} / \mathrm{s}$ (paper speed), $24 \mathrm{~h}$ ambulatory electrocardiographic monitorization (AECG), and transthoracic echocardiography by a Siemens Acuson Sequoia C256 cardiac ultrasonographic scanner, with 2.5 - to $3.5-\mathrm{MHz}$ transducers.

\section{Results}

It was noted that SDNN (standard deviation of all NN intervals) value was lower in patients with FMF as compared to the control group. Frequency-dependent HRV parameters were similar in both groups. There was no difference in patient and control groups in terms of conventional echocardiographic parameters.

\section{Conclusion}

Studies with larger cohorts and more comprehensive methods are required to assess the presence and consequences of possible autonomic dysfunction in children with FMF.

\section{Disclosure of interest \\ None declared.}

\section{Authors' details}

'Gulhane Military Medical Academy, Ankara, Turkey. ${ }^{2}$ Hacettepe University, Ankara, Turkey.

${ }^{1}$ Gulhane Military Medical Academy, Ankara, Turkey

Full list of author information is available at the end of the article 
- Convenient online submission

- Thorough peer review

- No space constraints or color figure charges

- Immediate publication on acceptance

- Inclusion in PubMed, CAS, Scopus and Google Scholar

- Research which is freely available for redistribution 